\title{
The Swedish dental health register - validation study of remaining and intact teeth
}

\author{
Rickard Ljung ${ }^{1 *}$ (D) Frida Lundgren², Marianne Appelquist ${ }^{2}$ and Andreas Cederlund ${ }^{3}$
}

\begin{abstract}
Background: Sweden has a long tradition of nationwide registers enabling population-based research of high quality and validity. We aimed to describe the content and validity of reported number of remaining and intact teeth in the Swedish Dental Health Register and report some descriptive data on dental health care utilization.

Methods: The Swedish Dental Health Register was initiated in July 1st 2008 and contains individual data on dental health care to the whole adult population of Sweden. The dental care given freely to children and young adults is not included. Descriptive data on remaining, intact teeth and dental health care utilization is presented by proportion of the population stratified by sex and age. We conducted a validation study, by manual review of randomly sampled 1500 dental health visits records, to assess reported number of teeth to the register with what was actually recorded in the dental health care record (gold standard), analyzed by positive predictive value (PPV) and Bland-Altman plots.

Results: Of the Swedish adult population 2014, 2.6 million (69\%) men and 2.9 million (76\%) women had at least one visit to a dentist during a two-year period 2013 to 2014. More than half of the population up to age 64 have all remaining teeth (28 teeth or more). Of the 1500 requested dental records 1131 (75\%) were received. The positive predictive value for patients reported to the register as having at least 1 tooth up to 31 intact teeth was 91.5\% (95\% confidence interval 89.0-93.5, 567 manually reviewed to be correct out of 620 reported).

Conclusions: For patients coded as having less than 32 intact teeth but not being edentulous the reported number of remaining and intact teeth is to a very high degree correct. However, the correctness for those coded as edentulous or having 32 remaining intact teeth is low and varies substantially by age.
\end{abstract}

Keywords: Caries, Dental health, Health care utilization, Inequalities in health

\section{Background}

Poor oral health as defined by diseases of the oral cavity, foremost periodontitis and caries, and limited number of remaining intact teeth constitutes a major global health burden. The distribution of poor oral health is socially patterned as shown by large socioeconomic disparities in oral health within and between countries. $[1,2]$ There is limited data on oral health and its determinants in the Swedish population [3], but there are indications of major social disparities. [3-8] A large part of the global population is not covered by dental health care, and in

\footnotetext{
* Correspondence: rickard.ljung@ki.se

'Unit of Epidemiology, Institute of Environmental Medicine, Karolinska

Institutet, PO Box 210, SE-171 77 Stockholm, Sweden

Full list of author information is available at the end of the article
}

settings with high coverage the utilization varies across socioeconomic groups. Sweden has universal free dental health care services for children and young adults up to the year of their 23rd birthday. For adults, from the year they turn 24 , dental health care services are financed by state subsidization and patient out-of-pocket payment and a small part by the county council for some specific group in the population. Dental care is to a large extent (60\% in the year 2014) financed by the consumers of dental care. [9-11]

Population-based registers facilitate high quality research provided that registration is complete and valid. There is a need for a national register with high coverage, completeness and validity to facilitate continuous monitoring of the distribution of dental health in the population, evaluation

(c) The Author(s). 2019 Open Access This article is distributed under the terms of the Creative Commons Attribution 4.0 International License (http://creativecommons.org/licenses/by/4.0/), which permits unrestricted use, distribution, and 
of dental health care treatment, and to enable studies of the association between dental health and other diseases. Sweden has a long tradition of nationwide population registers enabling population-based research of high quality. [12] In the other Nordic countries there has been national or regional registers on dental health foremost for children, including a Swedish register on dental implants and another for dental caries and periodontitis, but for long Sweden has not had a national register covering the adult population. [13-16] However, in 2008 the Swedish Dental Health Register was initiated. The register contains individual data on dental health care reimbursed by the State to the whole adult (23 years and older) population of Sweden. [17]

The data collection is administered by the Swedish Insurance Agency as part of the administration of the reimbursement from the State to dental health care facilities for dental services provided to the population. Information on dental health care is monthly transferred to the National Board of Health and Welfare, which is responsible for keeping all national health data registers. The Swedish Dental Health Register is regulated under a legislation issued by the Swedish government and can among others be used for evaluation and planning of health care services, monitoring public health and for research. Electronic reporting is mandatory for the dental health professions. [18]

We aim to describe the content and the validity of reported number of teeth of the Swedish Dental Health Register and to report some descriptive data on dental health care utilization.

\section{Method}

\section{Dental health care utilization}

In the descriptive analyses we used data from the Swedish Dental Health Register for the mean Swedish population in 2014. [19] Dental health care utilization measured as at least one visit during follow-up was calculated for a 1 year period (2014), a 2 year period (2013-2014) and a 3 year period (2012-2014). Due to some lag in reporting and corrections the register is continuously updated. Hence, later versions are more complete for a specific previous year. Also, at the time of the study Sweden had universal free dental health care services for children and young adults up to the year of their 19th birthday, hence we followed the adult population from age 20 and older. From 2017, upper age limit has been gradually expanded and as of 2019, dental care is free for children and young adults up to the year of their 23rd birthday.

\section{Content of the Swedish dental health register}

The register contains clinical data on number of remaining teeth and number of remaining intact teeth, and diagnoses and dental procedures. However, only diagnoses that are subject to an intervention or treatment during the dental visit are recorded. Classifications of diagnoses and dental procedures are determined by The Dental and Pharmaceutical Benefits Agency of Sweden. [20] The agency also determines the level of reimbursement for these procedures.

The register contains four basic categories of information:

Patient data: sex, age, place of residence, personal identity number, citizenship, country of origin, civil status.

Dental care data: name and address of dental clinic or dental practice.

Administrative data: dates of treatment, Clinical data: diagnoses, tooth number and position, type of procedure, number of remaining teeth, number of intact teeth.

\section{Validation of the quality of reported number of teeth} We conducted a validation study to compare data reported to the register with what was actually recorded in the dental health care record (gold standard). A total of 1500 dental health visits in the first 2 months of 2014 where selected by stratified random sampling from the Dental Health Register. A letter was sent to each clinic requesting a copy of the dental health care records for the sampled visits. Dental health care records were retrieved from both public and private dental clinics by post, either on paper copies or electronic files, and reviewed by a senior dental hygienist (MA) and a senior dentist (AC). The sampling was done in three different subsets; First, a random sample of 800 visits among those with reported at least 1 tooth up to 31 intact teeth, of these 620 were received (78\%), second a random stratified sample by age of 350 records of visits among patients reported with no teeth (edentulous) (received $N=225,64 \%$ ), and a random stratified sample by age of 350 records of visits among patient with reported all remaining and intact teeth (32 teeth) (received $N=286$, $82 \%$ ). Overall response rate was 75\% (1131 records received of 1500 sampled).

\section{Statistical analyses}

Data on utilization of dental health care from January 1st, 2012 to December 31st 2014 was presented as proportions stratified by sex and age for the whole Swedish population in 2014. Positive predictive values with 95\% confidence intervals, Bland-Altman plot, linear plot and Cohen's kappa coefficient with 95\% confidence intervals were used to present the results of the validation study. In the analyses of Cohen's kappa coefficient pseudoobservations were added to fill non-square tables with unused categories given a very small weight. 


\section{Results}

\section{Visit to dental services}

Of the Swedish adult population 2014, 2,560,000 (69\%) men and 2,860,000 (76\%) women had at least one visit to a dentist during a two-year period 2013 to 2014 (Table 1). In all age groups, except for those 75 years and older, women had a higher attendance to dental services than men. Around two thirds of young adults aged 20-24 had at least one visit in the last 3 years. The youngest and the very old had the lowest attendance to dental services. The highest attendance was among those aged $65-74$ years.

\section{Edentulous and remaining teeth}

More than half of the population up to age 64 had all remaining teeth $(28+)$ (Table 2 ). Less than $10 \%$ of those aged 85 and older had all remaining teeth and around 3 had no teeth left. Among those younger than 35 years around $10 \%$ had 20 intact teeth or less.

\section{Validation of reported remaining and intact teeth}

In total, 98 (43.6, 95\% CI 37.0-50.3) out of 225 retrieved dental health records coded as edentulous in the register were assessed as having no teeth based on the dental record. The coding was much better with increasing age; 85\% (73.4-92.9) of those 75 years and older coded as edentulous were assessed as correctly edentulous. Of the 286 patients coded as having 32 intact teeth in the register 69 (24.1, 95\% CI 19.3-29.5) were assessed as having 32 teeth based on the dental record. For 567 of the 620 records of patients coded as not being edentulous and having less than 32 remaining intact teeth the number of remaining teeth reported to the register was the same as the number of teeth assessed from the validation based on information in the dental record. This corresponds to a positive predictive value of 91.5\% (89.0-93.5) for remaining teeth. For 544 of the 620 records of patients coded as not being edentulous and having less than 32 remaining intact teeth the number of intact teeth reported to the register was the same as the number of intact teeth assessed from the validation based on information in the dental record. This corresponds to a positive predictive value of $87.7 \%$ (84.9-90.2) for intact teeth. (Table 3).

A Bland-Altman plot and a linear plot depict the agreement between registered and recorded number of teeth for remaining and intact teeth respectively (Fig. 1). The plots are based on records where numbers of teeth

Table 1 Proportion of the Swedish mean population in 2014, by sex and age, with at least one record in the Dental Health Register during a 1 year period (2014), a 1 year period (2013-2014) and a 3 year period (2012-2014)

\begin{tabular}{|c|c|c|c|c|c|c|c|}
\hline \multirow{3}{*}{\multicolumn{2}{|c|}{ Population }} & \multicolumn{6}{|c|}{ Proportion of the Swedish population 2014 with at least one record in the Dental Health Register } \\
\hline & & \multicolumn{2}{|l|}{$\ln 2014$} & \multicolumn{2}{|c|}{ In 2014 or 2013} & \multicolumn{2}{|c|}{ In 2014,2013 or 2012} \\
\hline & & $\mathrm{N}$ & $\%$ & $\mathrm{~N}$ & $\%$ & $\mathrm{~N}$ & $\%$ \\
\hline \multicolumn{8}{|l|}{ Women } \\
\hline $20-24$ & 327,449 & 150,177 & 45.9 & 206,211 & 63.0 & 222,314 & 67.9 \\
\hline $25-34$ & 609,532 & 278,785 & 45.7 & 400,398 & 65.7 & 450,367 & 73.9 \\
\hline $35-44$ & 616,173 & 334,433 & 54.3 & 447,810 & 72.7 & 488,905 & 79.3 \\
\hline $45-54$ & 633,789 & 397,260 & 62.7 & 497,411 & 78.5 & 530,721 & 83.7 \\
\hline $55-64$ & 571,302 & 411,739 & 72.1 & 477,309 & 83.5 & 497,770 & 87.1 \\
\hline $65-74$ & 541,010 & 422,405 & 78.1 & 473,032 & 87.4 & 488,600 & 90.3 \\
\hline $75-84$ & 317,377 & 221,146 & 69.7 & 255,062 & 80.4 & 268,135 & 84.5 \\
\hline $85+$ & 168,564 & 77,277 & 45.8 & 100,633 & 59.7 & 114,817 & 68.1 \\
\hline Total & $3,785,194$ & 2,293,222 & 60.6 & $2,857,866$ & 75.5 & $3,061,629$ & 80.9 \\
\hline \multicolumn{8}{|l|}{ Men } \\
\hline $20-24$ & 344,286 & 140,901 & 40.9 & 197,568 & 57.4 & 215,563 & 62.6 \\
\hline $25-34$ & 638,657 & 241,883 & 37.9 & 352,615 & 55.2 & 402,720 & 63.1 \\
\hline $35-44$ & 636,124 & 296,878 & 46.7 & 401,204 & 63.1 & 443,257 & 69.7 \\
\hline $45-54$ & 653,457 & 363,695 & 55.7 & 461,565 & 70.6 & 497,934 & 76.2 \\
\hline $55-64$ & 573,299 & 378,154 & 66.0 & 443,625 & 77.4 & 466,679 & 81.4 \\
\hline $65-74$ & 524,281 & 386,447 & 73.7 & 435,593 & 83.1 & 452,753 & 86.4 \\
\hline $75-84$ & 254,122 & 177,214 & 69.7 & 205,356 & 80.8 & 216,349 & 85.1 \\
\hline $85+$ & 87,193 & 47,280 & 54.2 & 61,433 & 70.5 & 69,120 & 79.3 \\
\hline Total & $3,711,418$ & $2,032,452$ & 54.8 & $2,558,959$ & 68.9 & $2,764,375$ & 74.5 \\
\hline
\end{tabular}


Table 2 Number of remaining teeth and intact teeth of the Swedish population 2014 by sex and age, presented as the number of teeth at the cutoff in the lowest decile (P10), median and highest decile (P90)

\begin{tabular}{|c|c|c|c|c|c|c|c|c|c|c|c|}
\hline & \multirow[b]{2}{*}{$\begin{array}{l}\text { Population } \\
2014\end{array}$} & \multirow[b]{2}{*}{$\begin{array}{l}\text { Patients with reported } \\
\text { teeth status in } 2014\end{array}$} & \multirow[b]{2}{*}{ Edentulous (\%) } & \multirow[b]{2}{*}{ All remaining (\%) } & \multicolumn{3}{|c|}{ Number remaining teeth } & \multirow[b]{2}{*}{ All intact (\%) } & \multicolumn{3}{|c|}{ Number intact teeth } \\
\hline & & & & & $\overline{P 10}$ & Median & P90 & & $\overline{P 10}$ & Median & P90 \\
\hline \multicolumn{12}{|l|}{ Women } \\
\hline $20-24$ & 326,946 & 148,027 & $341(0.23)$ & $26,724(18.1)$ & 27 & 28 & 32 & $9970(6.7)$ & 21 & 27 & 31 \\
\hline $25-34$ & 617,535 & 281,317 & $976(0.34)$ & $78,122(27.8)$ & 27 & 30 & 32 & $21,628(7.7)$ & 18 & 26 & 31 \\
\hline $35-44$ & 616,808 & 308,079 & $1003(0.33)$ & $64,519(20.9)$ & 26 & 29 & 32 & $12,249(4.0)$ & 14 & 22 & 29 \\
\hline $45-54$ & 636,427 & 351,776 & $1350(0.38)$ & $44,481(12.6)$ & 25 & 28 & 32 & $8229(2.3)$ & 9 & 17 & 26 \\
\hline $55-64$ & 569,342 & 346,538 & $1907(0.55)$ & $22,546(6.5)$ & 22 & 28 & 31 & $5806(1.7)$ & 4 & 11 & 21 \\
\hline $65-74$ & 547,625 & 348,819 & $3575(1.03)$ & $12,220(3.5)$ & 17 & 26 & 29 & $4850(1.4)$ & 0 & 7 & 15 \\
\hline $75-84$ & 319,868 & 183,328 & $4013(2.19)$ & $4334(2.4)$ & 10 & 23 & 28 & $2364(1.3)$ & 0 & 5 & 12 \\
\hline $85+$ & 168,707 & 63,581 & $2144(3.37)$ & $1837(2.9)$ & 6 & 20 & 27 & $1073(1.7)$ & 0 & 4 & 11 \\
\hline Total & $3,803,258$ & $2,031,465$ & $15,309(0.75)$ & $254,783(12.5)$ & 21 & 28 & 32 & 66,169 (3.3) & 3 & 16 & 28 \\
\hline \multicolumn{12}{|l|}{ Men } \\
\hline $20-24$ & 344,583 & 138,097 & $248(0.18)$ & $30,158(21.8)$ & 28 & 29 & 32 & $9537(6.9)$ & 21 & 27 & 31 \\
\hline $25-34$ & 647,598 & 245,128 & $785(0.32)$ & $77,694(31.7)$ & 28 & 30 & 32 & $19,376(7.9)$ & 19 & 26 & 31 \\
\hline $35-44$ & 637,674 & 271,750 & $914(0.34)$ & $68,013(25.0)$ & 27 & 30 & 32 & $11,464(4.2)$ & 14 & 22 & 30 \\
\hline $45-54$ & 656,361 & 319,785 & $1248(0.39)$ & $51,167(16.0)$ & 26 & 29 & 32 & $7481(2.3)$ & 10 & 18 & 27 \\
\hline $55-64$ & 571,928 & 317,030 & $1785(0.56)$ & $27,297(8.6)$ & 23 & 28 & 31 & $5228(1.7)$ & 4 & 12 & 21 \\
\hline $65-74$ & 530,770 & 317,950 & $3284(1.03)$ & $13,399(4.2)$ & 17 & 26 & 30 & $4224(1.3)$ & 1 & 8 & 17 \\
\hline $75-84$ & 258,137 & 146,409 & $3225(2.20)$ & $3939(2.7)$ & 10 & 23 & 28 & $1898(1.3)$ & 0 & 5 & 14 \\
\hline $85+$ & 87,777 & 38,616 & $1236(3.20)$ & $1086(2.8)$ & 7 & 20 & 27 & $618(1.6)$ & 0 & 4 & 13 \\
\hline Total & $3,734,828$ & $1,794,765$ & $12,725(0.71)$ & $272,753(15.2)$ & 21 & 28 & 32 & $59,826(3.3)$ & 3 & 17 & 29 \\
\hline
\end{tabular}

were possible to assess (599 for remaining teeth and 595 for intact teeth), hence for 21 out of the 620 records there was no information on remaining teeth and for 25 out of the 620 there was no information on intact teeth. For remaining teeth the simple kappa was 0.942 (95\% CI 0.923-0.962), and the weighted kappa 0.939 (0.910-0.969), for intact teeth the kappa was 0.913 $(0.890-0.936)$ and $0.949(0.930-0.967)$ respectively.

\section{Discussion}

The Swedish Dental Health Register provides near to complete national data on dental health care to the adult Swedish population. The positive predictive value of reported teeth is high among those with at least 1 tooth up to 31 intact teeth reported to the register. However, we have pinpointed two major areas where the quality of the register has to be improved considerably; recording of no teeth and recording of all remaining and intact teeth (32 intact teeth). In a random sample the positive predictive value was less than $50 \%$ in these groups.

\section{Strength and limitations}

The high quality and validity of the Dental Health Register together with the complete nationwide coverage is a unique source for dental health care services research. This also provides our study with high precision and

Table 3 Validation of number of remaining intact teeth as recorded in the Dental Health Register by assessment of retrieved dental health records, by number of remaining intact teeth reported to the Dental Health Register in 2014

\begin{tabular}{|c|c|c|c|c|c|c|c|c|c|}
\hline \multirow[b]{2}{*}{$\begin{array}{l}\text { Remaining intact teeth } \\
\text { according to register }\end{array}$} & \multirow[b]{2}{*}{$\begin{array}{l}\text { Records } \\
\text { sampled }\end{array}$} & \multirow[b]{2}{*}{$\begin{array}{l}\text { Records } \\
\text { recieved }\end{array}$} & & \multicolumn{6}{|c|}{ Agreement between dental health records and the register } \\
\hline & & & & Correct & $\begin{array}{l}\text { (positive predictive value) } \\
\%(95 \% \mathrm{Cl})\end{array}$ & Incorrect & $\%$ & $\begin{array}{l}\text { Cannot be } \\
\text { assessed }\end{array}$ & $\%$ \\
\hline 0 & 350 & 225 & & 98 & $43.6(37.0-50.3)$ & 124 & $(55)$ & 3 & {$[1]$} \\
\hline 32 & 350 & 286 & intact & 69 & $24.1(19.3-29.5)$ & 190 & $(66)$ & 27 & [9] \\
\hline \multirow[t]{2}{*}{$0<32$} & 800 & 620 & remaining & 567 & $91.5(89.0-93.5)$ & 38 & {$[6]$} & 15 & [2] \\
\hline & & & intact & 544 & 87.7 (84.9-90.2) & 59 & [9] & 17 & [3] \\
\hline
\end{tabular}



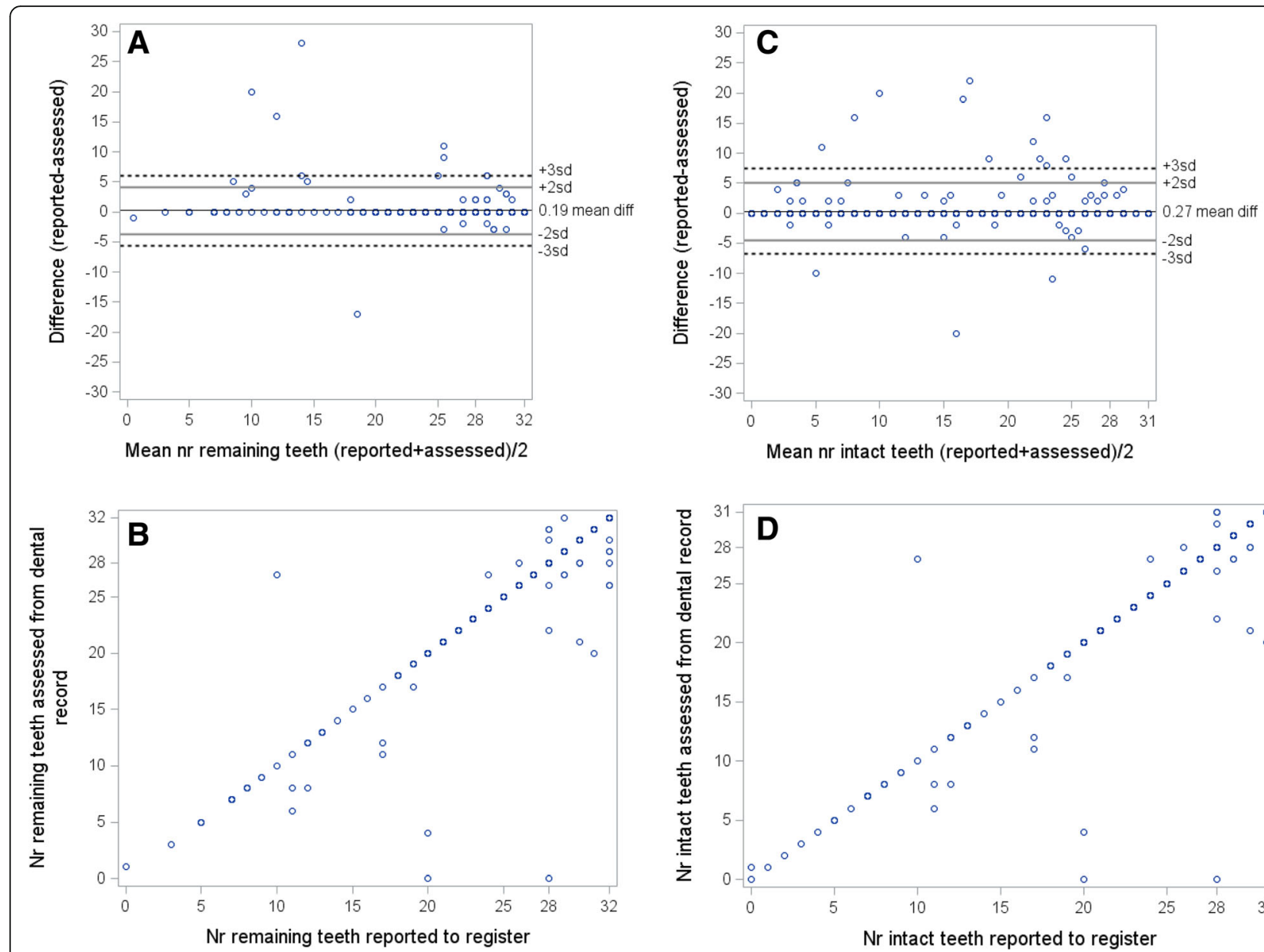

Fig. 1 Bland-Altman plots and linear plots of number of reported teeth and number of teeth assessed by manual review of dental health records (599 teeth assessed for comparison of remaining teeth and 595 teeth assessed for comparison of intact teeth). (1A) Bland-Altman plot of remaining teeth, (1B) linear plot of remaining teeth, (1C) Bland-Altman plot of intact teeth, (1D), linear plot intact teeth

considerable power in the estimates of the dental health and dental health care utilization of the Swedish population. The four largest computerized reporting systems used in dental health care services in Sweden have predefined default values of either no teeth or 32 teeth. Hence, we hypothesize that some dentists and dental hygienists by routine just click the default value ( 0 or 32$)$ instead of recording the actual correct number of remaining teeth. This is most probably the explanation of the low validity of 0 and 32 reported teeth. A possible improvement could be to have no default values and thus instead force the recorder to manually fill in the correct number of teeth. We have only validated the recorded number of teeth for that particular sampled dental visit. However, also taking previously recorded values of number of teeth into account would generate a higher concordance between recorded number of teeth and the correct number of teeth assessed by manual review. This indicates that there is no systematic misclassification of number of teeth due to patient or dentist or dental hygienist characteristics. The misclassification more seems to be non-differential. The overall response rate of the validation study was high (75\%). However, we cannot totally rule out differential response rate between dentists and dental hygienists recording correctly and those recording less correctly which might have overestimated the quality of the reported number of remaining teeth. The clinical data reported to the register is number of remaining teeth, intact teeth, diagnoses and procedures. However, we have only validated remaining teeth and intact teeth. We argue that remaining intact teeth is a simple and very useful measure of oral health (if the data is correct) to use for dental health surveillance and thus the most important data to validate. However, in the future we hope that reported specific diagnoses and procedures will be validated.

The reform of dental care that was introduced in 2008 included increased governmental subsidies. [9-11] For implementation of the dental reform, the Dental Health Register was introduced, making it necessary for the 
dentists to register their patients in a computerized system in order to get the subsidies paid out by the governmental agency in charge of the register. However, as the out-ofpocket payment can be substantial, patients with financial distress may opt not to seek dental health care when needed. We have no means to in a systematic way assess the oral health of those not registered in the register.

Until now the sources used for dental health research in Sweden have mainly been regional or local registers or specifically collected data in smaller studies; dental health in the population, [21-23] utilization of dental health care services [24], socioeconomic differences in utilization of health care services, [3-8, 25], risk factors for caries [26], dental health as a risk factor for other disease [27-29]. The Dental Health Register, with data on utilization by age and sex and possible to link to socioeconomic factors is a valuable and very powerful source for public health policy planning and future research on these topics. Linking the Dental Health Register to other national data will generate unique possibilities for research not possible in many other settings. [12, 18, 30-32]

\section{Conclusion}

For patients coded as having less than 32 remaining intact teeth but not being edentulous the reported number of remaining and intact teeth is to a very high degree correct. However, the correctness for those coded as edentulous or having 32 remaining intact teeth is low and varies substantially by age. The high validity of reported remaining and intact teeth in the Swedish Dental Health Register offers enormous potential for descriptive and analytical population-based dental health research.

\section{Abbreviations}

$\mathrm{Cl}$ : Confidence Interval; PPV: Positive Predictive Value

\section{Acknowledgements}

Not applicable.

\section{Consent to publish from the participants}

Not applicable.

\section{Author's contributions}

$\mathrm{RL}, \mathrm{AC}$ and $\mathrm{FL}$ drafted the protocol and statistical analysis plan. RL was main responsible for retrieval of dental records. $A C, F L, M A$ assisted in the retrieval of dental records. MA manually reviewed all dental records, AC assisted in the manual review. FL analyzed the data. RL drafted the paper. All authors revised the statistical analysis plan, reviewed the results, and revised the paper. RL is the principal investigator and guarantor and affirms that the manuscript is an honest, accurate, and transparent account of the study being reported; that no important aspects of the study have been omitted; and that any discrepancies from the study as planned (and, if relevant, registered) have been explained. All authors read and approved the final manuscript.

\section{Funding}

There was no external funding for this project.

\section{Availability of data and materials}

According to Swedish Law the data cannot be placed in a publicly available repository. Researchers can after ethical approval apply for data from the
National Board of Health and Welfare, Stockholm, Sweden at www. socialstyrelsen.se. The Swedish national registers offer great potential for population-based register research. We recommend researchers unfamiliar to register-based research and researchers from outside of Sweden to collaborate with experienced researchers in Sweden, the authors (Dr Ljung) can facilitate such contacts.

\section{Ethics approval and consent to participate}

The study was approved by the Regional Ethical Review Board in Stockholm, Sweden (no. 2014/874-31). According to Swedish Law there was no need for individual consent to participate.

\section{Competing interests}

FL is an employee and AC, RL and MA are former employees of the National Board of Health and Welfare, the holder of the Dental Health Register. R.L. is employed at the Swedish Medical Products Agency, SE-751 03 Uppsala, Sweden. The views expressed in this paper do not necessarily represent the views of the Government agencies.

\section{Author details}

'Unit of Epidemiology, Institute of Environmental Medicine, Karolinska Institutet, PO Box 210, SE-171 77 Stockholm, Sweden. ${ }^{2}$ National Board of Health and Welfare, Stockholm, Sweden. ${ }^{3}$ Public Dental Health Stockholm county council, Stockholm, Sweden.

Received: 4 February 2019 Accepted: 31 May 2019

Published online: 17 June 2019

References

1. Williams DM. Global oral health inequalities. J Dent Res. 2011;90(5):549-51.

2. Marmot M, Bell R. Social determinants and dental health. Adv Dent Res. 2011;23(2):201-6.

3. Nordenram G. Dental health in Sweden: the National Public Health Report 2012. Chapter 16. Scand J Public Health. 2012;40(Suppl 9):281-6.

4. Celeste RK, Nadanovsky P, Fritzell J. Trends in socioeconomic disparities in oral health in Brazil and Sweden. Community Dent Oral Epidemiol. 2011; 39(3):204-12.

5. Molarius A, Engström S, Flink H, Simonsson B, Tegelberg A. Socioeconomic differences in self-rated oral health and dental care utilisation after the dental care reform in 2008 in Sweden. BMC Oral Health. 2014;14:134. https://doi.org/10.1186/1472-6831-14-134.

6. Östberg AL, Kjellström AN, Petzold M. The influence of social deprivation on dental caries in Swedish children and adolescents, as measured by an index for primary health care: The Care Need Index. Community Dent Oral Epidemiol. 2017;45(3):233-41. https://doi.org/10.1111/cdoe.12281. Epub 2017 Jan 30.

7. Edman K, Öhrn K, Nordström B, Holmlund A. Prevalence of dental caries and influencing factors, time trends over a 30-year period in an adult population. Epidemiological studies between 1983 and 2013 in the county of Dalarna, Sweden. Acta Odontol Scand. 2016;74(5):385-92. https://doi.org/ 10.3109/00016357.2016.1163733. Epub 2016 May 24

8. Cederlund A, Lundgren F, Tranaus S, Norlund A. Caries treatment in Swedish adults: effectiveness, costs and equity. A 4-year follow-up study of data from the Swedish national dental health register. Swed Dent J. 2016:40(2):223-34

9. Pälvärinne R, Widström E, Forsberg BC, Eaton KA, Birkhed D. The healthcare system and the provision of oral healthcare in European Union member states. Part 9: Sweden. Br Dent J. 2018;224(8):647-51. https://doi.org/10. 1038/sj.bdj.2018.269.

10. Franzon B, Axtelius B, Åkerman S, Klinge B. Dental politics and subsidy systems for adults in Sweden from 1974 until 2016. BDJ Open. 2017;5(3): 17007. https://doi.org/10.1038/bdjopen.2017.7.eCollection2017.

11. Andås CA, Hakeberg M. Payment systems and oral health in Swedish dental care: Observations over six years. Community Dent Health. 2016;33(4):25761. https://doi.org/10.1922/CDH_3843Andas05.

12. Rosén M. National Health Data Registers: a Nordic heritage to public health. Scand J Public Health. 2002;30(2):81-5.

13. Christensen LB, Petersen PE, Steding-Jessen M. Consumption of dental services among adults in Denmark 1994-2003. Eur J Oral Sci. 2007;115(3):174-9.

14. Skeie MS, Klock KS. Scandinavian systems monitoring the oral health in children and adolescents; an evaluation of their quality and utility in the 
light of modern perspectives of caries management. BMC Oral Health. 2014;14:43.

15. Klinge B, Lundström M, Rosén M, Bertl K, Klinge A, Stavropoulos A. Dental Implant Quality Register-A possible tool to further improve implant treatment and outcome. Clin Oral Implants Res. 2018;29(Suppl 18):145-51. https://doi.org/10.1111/clr.13268.

16. The Swedish quality registry for caries and periodontal disease. www. skapareg.se. Accessed 12 June 2019.

17. Dental Health Register Statistics. Socialstyrelsen. https://www.socialstyrelsen. se/statistik-och-data/register/alla-register/tandhalsoregistret/. Accessed 12 June 2019.

18. [Decree on the Dental Health Register, in Swedish]. Förordning $(2008,194)$ om tandhälsoregister hos Socialstyrelsen. www.riksdagen.se/sv/dokumentlagar/dokument/svensk-forfattningssamling/forordning-2008194-omtandhalsoregister-hos_sfs-2008-194. Accessed 12 June 2019.

19. Ludvigsson JF, Autio G, Almqvist C, Edstedt-Bonamy AK, Ljung R, Michaelsson K, Neovius M, Stephansson O, Ye W. Registers of the Swedish Total population and their use in medical research. Eur J Epidemiol. 2016;31(2):125-36.

20. The dental and pharmaceutical benefits Agency of Sweden. www.tlv.se. Accessed 12 June 2019.

21. Zimmerman M. Oral health in groups of refugees in Sweden. Swed Dent Suppl. 1993;94:1-40.

22. Nederfors T, Paulsson G, Isaksson R, Fridlund B. Ability to estimate ora health status and treatment need in elderly receiving home nursing--a comparison between a dental hygienist and a dentist. Swed Dent J. 2000;24(3):105-16

23. De Palma P, Frithiof L, Persson L, Klinge B, Halldin J, Beijer U. Oral health of homeless adults in Stockholm, Sweden. Acta Odontol Scand. 2005;63(1):50-5.

24. Holst A, Braune K, Kjellberg-Larsson M. Occurrence and distribution of caries in 6-year-old children in Blekinge, Sweden. Swed Dent J. 1999;23(2-3):71-6.

25. Widström $E$, Martinsson T. Comparison of use of dental services by finnish immigrants and Swedes using national health statistics. Community Dent Oral Epidemiol. 1983;11(5):266-70.

26. Julihn A, Ekbom A, Modéer T. Maternal overweight and smoking: prenatal risk factors for caries development in offspring during the teenage period. Eur J Epidemiol. 2009:24(12):753-62

27. Tabrizi F, Buhlin K, Gustafsson A, Klinge B. Oral health of monozygotic twins with and without coronary heart disease: a pilot study. J Clin Periodontol. 2007;34(3):220-5.

28. Holm-Pedersen P, Avlund K, Morse DE, Stoltze K, Katz RV, Viitanen M, Winblad B. Dental caries, periodontal disease, and cardiac arrhythmias in community-dwelling older persons aged 80 and older: is there a link? J Am Geriatr Soc. 2005;53(3):430-7.

29. Holm-Pedersen P, Schultz-Larsen K, Christiansen N, Avlund K. Tooth loss and subsequent disability and mortality in old age. J Am Geriatr Soc. 2008;56(3):429-35.

30. Brooke HL, Talbäck M, Hörnblad J, Johansson LA, Ludvigsson JF, Druid $\mathrm{H}$, Feychting M, Ljung R. The Swedish cause of death register. Eur J Epidemiol. 2017;32(9):765-73. https://doi.org/10.1007/s10654-017-0316-1. Epub 2017 Oct 5.

31. Ludvigsson JF, Andersson E, Ekbom A, Feychting M, Kim JL, Reuterwall C, Heurgren M, Olausson PO. External review and validation of the Swedish national inpatient register. BMC Public Health. 2011;11:450. https://doi.org/ 10.1186/1471-2458-11-450

32. Wettermark B, Hammar N, Fored CM, Leimanis A, Otterblad Olausson P, Bergman U, Persson I, Sundström A, Westerholm B, Rosén M. The new Swedish prescribed drug register--opportunities for pharmacoepidemiological research and experience from the first six months. Pharmacoepidemiol Drug Saf. 2007;16(7):726-35.

\section{Publisher's Note}

Springer Nature remains neutral with regard to jurisdictional claims in published maps and institutional affiliations.

Ready to submit your research? Choose BMC and benefit from:

- fast, convenient online submission

- thorough peer review by experienced researchers in your field

- rapid publication on acceptance

- support for research data, including large and complex data types

- gold Open Access which fosters wider collaboration and increased citations

- maximum visibility for your research: over $100 \mathrm{M}$ website views per year

At $\mathrm{BMC}$, research is always in progress.

Learn more biomedcentral.com/submissions 